\title{
Obesity: A Concise Review and Key Points
}

\author{
Eliane Malek* and Rina Lazebnik \\ Department of Pediatrics, University Hospitals Rainbow Babies and Children's Hospital and school of Medicine, Case Western Reserve University, USA
}

*Corresponding author: Eliane Malek, Department of Pediatrics, University Hospitals Rainbow Babies and Children's Hospital and school of Medicine, Case Western Reserve University, Cleveland, Ohio, USA.
Received Date: July 16, 2020

Published Date: July 31, 2020

\section{Introduction}

Obesity is associated with significant morbidity in the pediatric population [1]. The COVID-19 pandemic had significant impact on individual's lifestyle. Therefore, obesity rates may increase even more in our current times [2]. There is a need to consider this problem and therefore we want to provide a concise summary about obesity for the general pediatrician. This review is a summary of key points in obesity diagnosis, risk factors, complications, prevention, and treatment.

Keywords: Obesity; Pediatric; Childhood; Adolescent; Morbidity; Review

\section{Definition and Epidemiology}

Obesity is defined in the less than 2 years of age by weight to recumbent length $\geq 97.7$ th percentile of the WHO growth chart. In the 2 years of age and older, obesity is diagnosed by BMI $\geq 95^{\text {th }}$ percentile [3] (Table 1). The prevalence of obesity as estimated by the most recent CDC report in June 2019 varies by age group as follows $13.9 \%$ in the $2-5$ years, $18.4 \%$ in the $6-11$ years and $20.6 \%$ in the 12-19 years age groups. Moreover, obesity rates are affected by gender, ethnicity, and socioeconomic class, with the highest prevalence in low-middle income group and Non-Hispanics black and Hispanics.

\section{Morbidity}

A meta-analysis by Llewellyn et al showed that there is a significant and positive association between childhood BMI increase and prediction of adulthood morbidities [4]. For a one standard deviation increasein BMIinobesechildren who are 12yearsandolder, the odds ratio (OR) for DM2 is 1.7 (95\% CI 1.3-2.22), CHD OR is 1.3 (95\% CI 1.16-1.47), stroke OR 1.06 (95\% CI 1.04-1.09), HTN OR 1.29 (95\% CI 1.19-1.4) . In addition, childhood obesity poses increased risks during childhood for developing depression and low self- esteem [5], OSA [4], as well as fatty liver disease, galls stones and GERD [6].

\section{Prevention and Treatment}

To avoid the morbidities associated with obesity, prevention is essential. The general pediatrician has a key role in promoting education to prevent and treat childhood obesity. Education includes family centered approach (child and all involved care givers), school and community. Lifestyle includes increasing physical activity to improve metabolism (Table 1) and improving dietary practices such as decreasing fast food, limiting or eliminating sweetened and flavored drinks, avoidance of fatty food, portion control, structured meal plan for the day instead of grazing, increase fibers and vegetable intake, as well as having a structured meal time and avoiding eating while watching television. Pharmacotherapy should be reserved for patients who failed lifestyle interventions and have associated morbidities [1]. Recently, a randomized study by Kelly et al. showed promising results in the 12-18 year-old obese patients [7]. The data demonstrated that Liraglutide in addition to life style modification resulted in significant reduction in BMI 
compared to life style modification alone [7]. For extreme obesity cases in adolescents who reached Tanner 4-5 and final adult height, who did not respond to formal and strict lifestyle changes and have confirmation of stable psychologic status of self and family with adequate adherence to follow up, bariatric surgery can be an option [1]. In addition, attention should be paid to recognizing diseases associated with obesity as this can have a substantial impact on treatment options (Figure 1).

Table 1: Summary of key points of Childhood obesity.

\begin{tabular}{|c|c|c|c|c|}
\hline Diagnosis & Risk Factors [3] & Complications [4] & Prevention & Treatment [1] \\
\hline $\begin{array}{c}<2 \text { years, Weight: Recumbent length } \geq 97.7^{\text {th }} \text { percentile } \\
\text { of WHO growth chart }\end{array}$ & Lifestyle & HTN & Education $\dagger$ & Lifestyle changes \\
\hline$\geq 2$ years, & Eating habits & DM2 & Physical activity $\mathbb{T}$ & Diet control \\
\hline $\begin{array}{c}\text { Overweight [3]: BMI } \geq 85^{\text {th }} \text { to }<95^{\text {th }} \text { percentile of CDC } \\
\text { chart }\end{array}$ & $\mathrm{PA}$ & OSA & Limit screen time & Increase PA \\
\hline Obesity [3]: BMI $\geq 95^{\text {th }}$ percentile & Environment & CHD & Sleep hygiene & Psychotherapy $\ddagger$ \\
\hline \multirow[t]{5}{*}{$\begin{array}{l}\text { Severe obesity [8]: BMI } \geq 120 \% \text { of the } 95^{\text {th }} \text { percentile } \\
\text { or BMI }>35 \mathrm{Kg} / \mathrm{m}^{2} .\end{array}$} & Socioeconomic factors & Stroke & Breastfeeding & Pharmacotherapy $\Psi$ \\
\hline & Genetic & Fatty liver & & Bariatric surgery \\
\hline & Endocrine & Gall stones & & \\
\hline & & GERD & & \\
\hline & & Cancer $\Phi$ & & \\
\hline \multicolumn{5}{|c|}{ Ф Hepatocellular carcinoma, renal cell carcinoma, colorectal carcinomas, urothelial carcinomas } \\
\hline \multicolumn{5}{|c|}{ †Education: assessment of family stressors, involving the entire family in the plan, school-based education } \\
\hline \multicolumn{5}{|c|}{ I 20 to 60 minutes of vigorous physical activity $\geq 5$ days/week } \\
\hline \multicolumn{5}{|c|}{ ‡ Psychotherapy: counseling for patients and family social and psychological problems } \\
\hline \multicolumn{5}{|c|}{$\Psi$ FDA approved: Lorcaserin, Liraglutide, Phentermine plus topiramate, Bupropion plus naltrexone, Orlistat, Metformin } \\
\hline
\end{tabular}

PA: Physical Activity, HTN: Hypertension, DM2: Diabetes Mellitus Type 2, OSA: Obstructive Sleep Apnea, CHD: Coronary Heart Disease, GERD: Gastroesophageal Reflux Disease

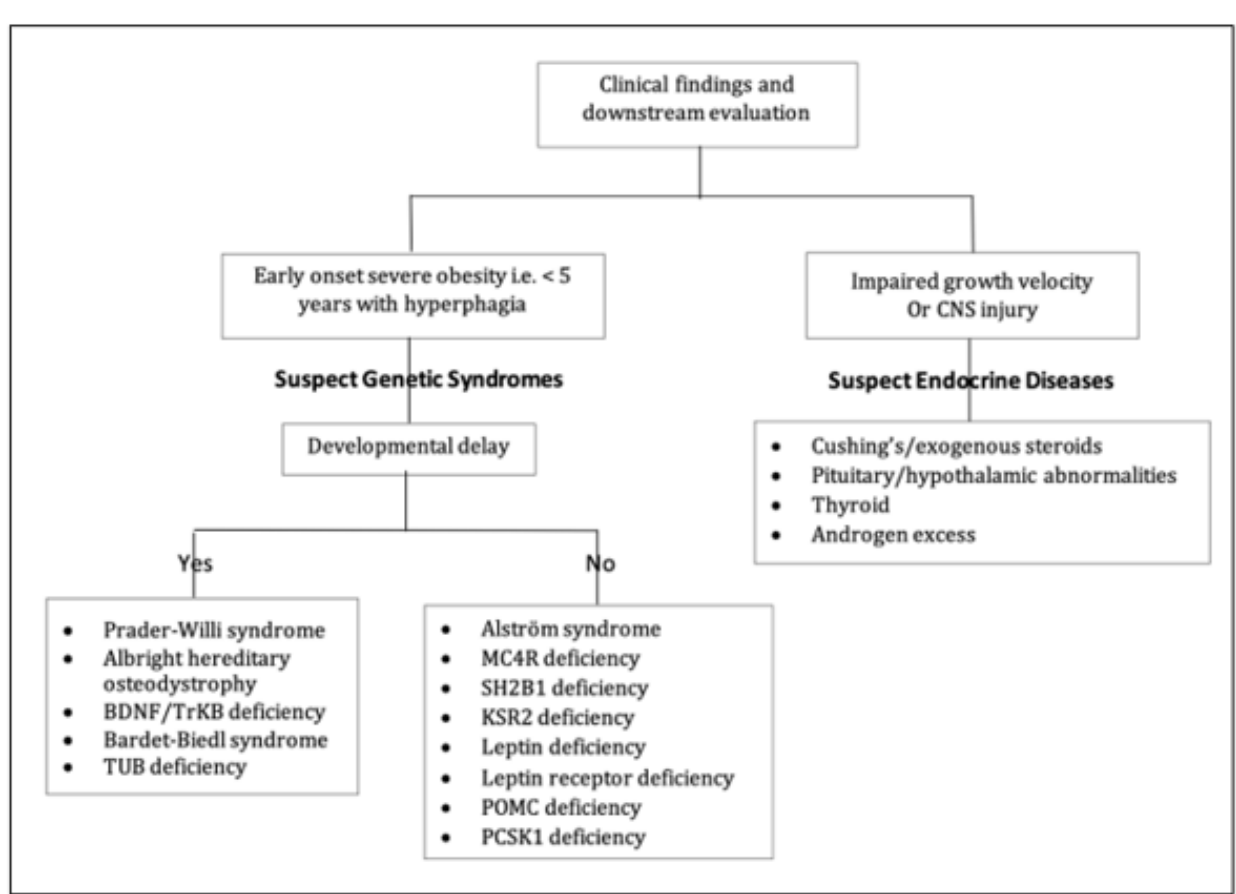

Figure 1: Flowchart of a simplified approach to obesity syndromes.

\section{Conclusion}

In summary, obesity presents a growing challenge in the pediatric population. It is essential that clinicians be able to appropriately diagnose and educate families to prevent immediate obesity consequences in childhood and the long-term morbidities in adulthood.

\section{Acknowledgement}

None. 


\section{Conflict of Interest}

\section{No conflict of interest.}

\section{References}

1. Styne DM, Arslanian SA, Connor EL, Farooqi IS, Murad MH, et al. (2017) Pediatric Obesity-Assessment, Treatment, and Prevention: An Endocrine Society Clinical Practice Guideline. J Clin Endocrinol Metab 102(3): 709757.

2. Pietrobelli A, Pecoraro L, Ferruzzi A, Heo M, Faith M, et al. (2020) Effects of COVID-19 Lockdown on Lifestyle Behaviors in Children with Obesity Living in Verona, Italy: A Longitudinal Study. Obesity (Silver Spring).

3. Barlow SE, Expert Committee (2007) Expert committee recommendations regarding the prevention, assessment, and treatment of child and adolescent overweight and obesity: summary report. Pediatrics 120 (Suppl 4): S164-S192.
4. Llewellyn A, Simmonds M, Owen CG, Woolacott N (2016) Childhood obesity as a predictor of morbidity in adulthood: a systematic review and meta-analysis. Obes Rev 17(1): 56-67.

5. Morrison KM, Shin S, Tarnopolsky M, Taylor VH (2015) Association of depression \& health related quality of life with body composition in children and youth with obesity. J Affect Disord 172: 18-23.

6. Africa JA, Newton KP, Schwimmer JB (2016) Lifestyle Interventions Including Nutrition, Exercise, and Supplements for Nonalcoholic Fatty Liver Disease in Children. Dig Dis Sci 61(5): 1375-1386.

7. Kelly AS, Auerbach P, Barrientos-Perez M, Gies I, Hale PM, et al. (2020) A Randomized, Controlled Trial of Liraglutide for Adolescents with Obesity. N Engl J Med 382(22): 2117-2128.

8. Kelly AS, Barlow SE, Rao G, Inge TH, Hayman LL, et al. (2013) Severe obesity in children and adolescents: identification, associated health risks, and treatment approaches: a scientific statement from the American Heart Association. Circulation 128(15): 1689-1712. 